\title{
Lembar Kerja Siswa (LKS) Pada Mata Pelajaran Matematika Materi Bangun Datar Kelas IV
}

\section{Titik Milu Hidayanti1*, Siti Quratul Ain²}

1,2 Universitas Islam Riau, Indonesia

\section{A R T I C L E I N F O}

Article history:

Received June 09, 2021

Revised June 15, 2021

Accepted July 15, 2021

Available online August 25, 2021

Kata Kunci:

LKS, Matematika, Bangun Datar

Keywords:

LKS, Mathematics, Flat Shape

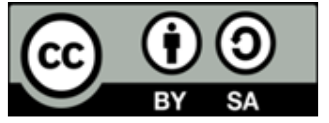

This is an open access article under the CCBY-SA license.

Copyright () 2021 by Author. Published by Universitas Pendidikan Ganesha.

\begin{abstract}
A B S T R A K
Penelitian ini bertujuan untuk menguji kelayakan LKS pada mata pelajaran Matematika dengan muatan materi bangun datar kelas IV SD. Penelitian ini merupakan penelitian pengembangan menggunakan model ADDIE. Tahapan model ADDIE untuk mengembangkan LKS ini dimodifikasi menjadi empat tahapan yaitu analysis, design, development, impementasi. Data yang dikumpulkan dalam penelitian ini adalah data kuantitatif dan data kualitatif. Metode yang digunakan untuk mengumpulkan data yaitu: metode observasi, wawancara, dan angket. Subjek yang terlibat dalam penelitian ini adalah 2 ahli desain, 2 ahli materi dan 2 ahli bahasa, 2 guru dan 6 orang siswa. Teknik analisis data yang digunakan adalah teknik analisis data deskriptif kuantitatif dan kualitatif. Hasil penelitian menunjukkan bahwa kelayakan LKS dari aspek desain memperoleh persentase $87,5 \%$ dengan kualifikasi valid, pada aspek materi pembelajaran matematika memperoleh persentase $83,25 \%$ dengan kualifikasi valid dan pada aspek bahasa memperoleh persentase $85,57 \%$ dengan kualifikasi valid. Selanjutnya, diperoleh persentase rata-rata akhir pengujian validasi LKS sebesar 85,44\% dalam kategori valid. Kemudian analisis dari angket respon guru kelas IV terhadap LKS memperoleh rata-rata sebesar 92,93\% dengan kategori "Sangat Menarik" sedangkan analisis dari angket respon peserta didik memperoleh rata-rata sebesar $93,33 \%$ dengan kategori "Sangat Menarik".
\end{abstract}

\section{A B S T R A C T}

This study aims to test the feasibility of student worksheets in mathematics subjects with the content of flat shape material for fourth-grade elementary school. This research is development research using the ADDIE model. The stages of the ADDIE model to develop LKS are modified into four stages, namely analysis, design, development, implementation. The data collected in this study are quantitative data and qualitative data. The methods used to collect data are observation, interviews, and questionnaires. The subjects involved in this study were 2 design experts, 2 material experts, and 2 linguists, 2 teachers, and 6 students. The data analysis technique used is quantitative and qualitative descriptive data analysis techniques. The results showed that the feasibility of LKS from the design aspect obtained a percentage of $87.5 \%$ with valid qualifications, in the mathematics learning material aspect it obtained a percentage of $83.25 \%$ with valid qualifications, and in the language aspect it obtained a percentage of $85.57 \%$ with valid qualifications. Furthermore, the final average percentage of $L K S$ validation testing is $85.44 \%$ in the valid category. Then the analysis of the fourthgrade teacher response questionnaire to the LKS obtained an average of $92.93 \%$ in the "Very Interesting" category while the analysis of the student response questionnaire obtained an average of 93.33\% in the "Very Interesting" category.

\section{PENDAHULUAN}

Pembelajaran adalah sebuah proses ilmiah mulai dari mengatur dan mengorganisasi lingkungan yang ada di sekitar peserta didik, sehingga dapat menumbuhkan dan mendorong peserta didik untuk melakukan suatu kegiatan belajar (Mustika, 2017; Pane \& Dasopang, 2017). Pembelajaran yang baik adalah pembelajaran yang melibatkan peserta didik secara aktif di dalamnya dan membuat peserta didik senang, termotivasi serta merasa tertarik untuk belajar mengenai sesuatu yang baru, sehingga peserta didik mampu membangun pengetahuannya sendiri dan membuat pembelajaran menjadi 
bermakna(Faridah et al., 2019; Widyanto, 2020). Pembelajaran yang bermakna akan memberikan pengalaman dan mampu mengembangkan emosional siswa yang nanti bisa digunakan dalam kehidupan sehari-hari (Bressington et al., 2018; Kostiainen et al., 2018). Menciptakan pembelajaran yang bermakna tidak terlepas dari peran guru. Peran guru tidak hanya bertanggung jawab dalam mendidik dan mengajar, tetapi guru juga berperan dalam menyiapkan perangkat pembelajaran. Kreativitas guru dalam merancang perangkat pembelajaran sangat berpengaruh terhadap berhasil atau tidaknya proses pembelajaran yang akan dilaksanakan. Salah satu perangkat pembelajaran yang perlu dirancang dan disiapkan oleh guru adalah Lembar Kerja Siswa (LKS).

Lembar kerja siswa sangatlah membantu peserta didik memahami materi. LKS merupakan salah satu alat untuk membantu dan memudahkan kegiatan pembelajaran, sehingga terbentuk interaksi yang efektif antara pendidik dan peserta didik. Keberadaan LKS memberi dampak yang cukup besar dalam proses kegiatan belajar mengajar. Lembar kerja siswa dapat menjadi panduan siswa dalam melakukan aktivitas pembelajaran (Andarika \& Widowati, 2017; Ardina \& Sa'dijah, 2016). Penggunaan LKS dalam proses pembelajaran mampu membuat siswa belajar lebih mandiri (Hamdu \& Rostiana, 2020; Pratiwi \& Yulkifli, 2019). LKS mampu mempermudah siswa mengonstruksi pengetahuan, memiliki retensi, dan meningkatkan hasil belajar siswa(Hala et al., 2016; Suryani et al., 2019). LKS yang digunakan haruslah efektif dan efisien serta mampu menjawab kebutuhan siswa dalam memahami suatu materi pembelajaran(Hasanah et al., 2019). Jadi, adanya LKS dapat meningkatkan proses pembelajaran, sehingga penyusunan LKS harus memenuhi berbagai persyaratan tertentu agar menjadi LKS yang berkualitas. Penyusunan LKS dapat dirancang sesuai dengan kondisi kegiatan yang akan dilakukan dan memerhatikan perkembangan dan karakteristik peserta didik (Gitriani et al., 2018). Selain itu, dalam merancang LKS harus memerhatikan materi yang ingin disampaikan. Dengan mengerjakan LKS tersebut, guru dapat mengamati peserta didik yang telah memahami materi yang telah diberikan dan yang belum memahami materi yang diberikan (Widodo, 2017). Jadi, adanya LKS yang sesaui dengan karakteristik peserta didik akan sangat membatu peserta didik dalam proses pembelajaran.

Namun, kenyataan di lapangan menunjukkan bahwa belum tersedianya lembar kerja siswa yang menekankan pada kegiatan percobaan dan observasi yang berdasarkan pendekatan saintifik (Septina et al., 2018). Berdasarkan analisis awal yang dilakukan, diketahui bahwa lembar kerja siswa (LKS) yang digunakan kurang menarik. Hal ini dibuktikan dengan tampilan LKS hanya berupa butiran soal tanpa adanya gambar dan warna yang bervariasi. Hal ini mengakibatkan siswa merasa cepat bosan dalam belajar. Guru hanya memberikan tugas menggunakan buku dari pemerintah. Berdasarkan hasil pengamatan, bentuk lainnya dalam pemberian tugas yang sering guru lakukan ialah dengan memanfaatkan media konvensional saja, seperti mencatat tugas di papan tulis kemudian siswa mencatat tugas tersebut di buku mereka masing-masing. Hal ini mengakibatkan pembelajaran yang dilaksanakan kurang maksimal. Misalnya, penulisan tugas yang berukuran kecil dapat menyulitkan siswa yang duduk di belakang untuk melihatnya. Di samping itu, pembelajaran yang dilakukan guru dalam memberikan tugas kepada siswa hanya menggunakan buku dari pemerintah (kemendikbud), yaitu berupa buku guru dan buku siswa. Kondisi ini berdampak terhadap hasil belajar siswa rendah. Ini dibuktikan dengan pencapaian sekitar $60 \%$ nilai rata rata siswa yang tidak mencapai kriteria ketuntasan minimal (KKM) yang telah ditetapakan guru yaitu 76. LKS yang digunakan oleh guru belum mengantarkan pada permasalahan kontekstual sebagai titik awal pembelajaran, sehingga di dalam pembelajaran peserta didik kurang aktif dan kurang memahami materi yang diberikan oleh guru(Septian et al., 2019). Jika masalah ini dibiarkan akan berdampak terhadap kualitas pembelajaran, hasil belajar, dan outcame pendidikan.

Untuk mengatasi hal tersebut tentunya menuntut pengembangan LKS yang sesaui dengan kurikulum, karakter peserta didik dan menarik. Dengan LKS yang lebih efektif dan menarik akan melatih kemandirian siswa dalam proses pembelajaran yang mencerminkan siskap kreatif, kritis, dan lebih bertanggungjawab (Fajriyanti et al., 2018). LKS dapat meningkatkan keterampilan belajar siswa dengan pola pikir yang terbuka, kritis, dan aktif dalam proses pembelajaran (Priscylio et al., 2019). Pentingnya peran LKS banyak digunakan dalam proses pembelajaran serta banyak penelitian yang sudah mengolaborasikan LKS yang menyatakan bahwa LKS tersebut efektif digunakan dalam proses pembelajaran. Penelitian-penelitian itu antara lain, penelitian yang menyatakan bahwa LKPD yang didesain dan diujicobakan kepada siswa kelas VII di salah satu sekolah di Soppeng telah memenuhi kriteria valid, efektif, dan praktis (Basri et al., 2020). Penelitian yang menyatakan bahwa Lembar Kerja Siswa (LKS) pada materi Limas yang dikembangkan menggunakan pendekatan Pendidikan Matematika Realistik Indonesia (PMRI) untuk siswa kelas VIII SMP terkategori valid, praktis, dan efektif (Isnaini \& Afgani, 2017). Penelitian yang menyatakan bahwa pengembangan LKS learning cycle $7 e$ dalam meningkatkan berpikir kritis siswa di sekolah dasar dikategorikan valid, praktis, dan efektif digunakan (Yaldi \& Sukriadi, 2019). Penelitian yang menyatakan bahwa LKS model blended learning yang berorientasi HOTS pada pokok bahasan impuls dan momentum layak untuk dipakai dalam kegiatan 
pembelajaran (Paradita \& Suana, 2019). Jadi, jabaran-jabaran tersebut memberikan gambaran bahwa dengan mengembangkan LKS sesuai dengan kurikulum, karakter siswa yang dibuat lebih menarik sangat berdampak terhadap pembelajaran. Oleh sebab itu, dalam penelitian ini akan dikembangkan LKS dengan materi bangun datar. Penelitian ini bertujuan untuk mengembangkan Lembar Kerja Siswa (LKS) pada Mata Pelajaran Matematika materi bangun datar Kelas IV SDN 114 Pekanbaru. Dengan mengembangkan LKS ini diharapakan dapat mengatasi masalah rendahnya hasil belajar siswa yang diakibatkan oleh sumber belajar yang tidak layak.

\section{METODE}

Jenis penelitian yang akan digunakan peneliti adalah penelitian dan pengembangan (Research and Development). penelitian ini merupakan upaya untuk mengembangkan ilmu pengetahuan dan mendapat temuan-temuan yang baru. Penelitian ini dipilih karena peneliti mengembangkan produk berupa alat bantu pembelajaran. Penelitian dan pengembangan akan menghasilkan produk berupa lembar kerja siswa (LKS) yang berisi ringkasan materi dan berbagai penugasan pada mata pelajaran Matematika, kemudian dijadikan alternatif yang tentunya akan melalui tahap pengujian terlebih dahulu. Dalam mengembangan LKS peneliti menggunakan model ADDIE, model desain pembelajaran yang sifatnya lebih generik yaitu model ADDIE (Analysis-Design-Delevop-Implement-Evaluate). Model ADDIE muncul pada tahun 1990-an yang dikembangkan oleh Reiser dan Mollena. Model ADDIE ada lima fase atau tahap yang perlu dilakukan secara sistematis dan sistemik. Tahapan model ADDIE untuk mengembangkan LKS ini dimodifikasi menjadi empat tahapan yaitu analisis, design, development dan implementasi. 1 tahap lagi tidak bisa dilakukan karena situasi pandemi covid-19 saat ini. Lokasi penelitian ini dilaksanakan di di Sekolah Dasar Negeri 114 Pekanbaru, Jl. Cempedak, Wonorejo, Kec. Marpoyan Damai, Kota Pekanbaru, Provinsi Riau. Teknik pengumpulan data ada tiga, yaitu angket kebutuhan. Pengembangan produk ini akan dianalisis menggunakan deskriptif kualitatif dengan cara penyajian data melalui beberapa pertanyaan sesuai dengan keadaan dan kebutuhan yang ada pada saat penelitian tanpa adanya penghitungan di dalamnya. Semua itu dijabarkan dalam bentuk deskriptif. Angket validasi yang akan diberikan kepada ahli materi, bahasa, serta desain dan guru. Pada penelitian dan pengembangan ini digunakan skala Likert. Analisis kuantitatif merupakan analisis hasil pemberian soal yang menghasilkan skor. Untuk menentukan kriteria dalam menentukan hasil validasi, ditunjukkan pada tabel 1. Angket tanggapan digunakan untuk mengumpulkan data mengenai tanggapan peserta didik terhadap LKS yang dikembangkan dengan menggunakan Skala Guttman. Skala Guttman merupakan skala yang digunakan untuk jawaban yang bersifat jelas (tegas) dan konsisten. Misalnya: Yakin-Tidak Yakin; Ya-Tidak; BenarSalah; Positif-Negatif; Penah-Belum Pernah; Setuju-Tidak Setuju; dan lain sebagaianya.

Tabel 1. Tingkat Kevalidan dan Revisi Produk

\begin{tabular}{cl}
\hline Persentase (\%) & Kriteria Valid \\
\hline $76-100$ & Valid (tanpa revisi) \\
$56-75$ & Cukup valid (tanpa revisi) \\
$40-55$ & Kurang valid (revisi) \\
$0-39$ & Tidak valid (revisi) \\
\hline
\end{tabular}

Sumber: Listiawan (2016)

\section{HASIL DAN PEMBAHASAN}

\section{Hasil Penelitian}

Berdasarkan validasi produk ini dilakukan dengan cara menghadirkan beberapa pakar atau tenaga ahli yang sudah berpengalaman untuk menilai lembar kerja siswa (LKS) pada mata pelajaran Matematika dengan materi bangun datar yang telah dibuat oleh peneliti. Peneliti meminta penilaian dari dua orang ahli media, dua orang ahli materi, dua orang ahli bahasa, dua orang wali kelas IV dan enam orang peserta didik. Adapun data yang diperoleh dalam penelitian ini sebagai berikut: Pertama, validasi desain dilakukan dengan dua orang ahli dalam menilai desain. Penghitungan persentase pada validasi pertama diperoleh rata-rata skor sebesar 81,67\% (Valid). Setelah LKS direvisi berdasarkan saran dan komentar yang diperoleh dari hasil validasi pertama, maka selanjutnya akan dilakukan validasi kedua dengan memperoleh rata-rata skor sebesar 93,33\% (Valid). Selanjutnya, diperoleh rata-rata akhir uji validasi desain sebesar 87,5 (Valid) Hasil penghitungan validasi pertama dan kedua lembar kerja siswa 
(LKS) sudah sangat layak digunakan untuk pembelajaran. Semua data dari hasil review, penilaian, dan diskusi dengan ahli desain dijadikan bahan pertimbangan penyempurnaan komponen lembar kerja siswa (LKS) sebelum digunakan oleh siswa.

Kedua, validasi materi dilakukan oleh dua orang ahli dalam menilai isi materi. Penghitungan persentase pada validasi pertama diperoleh rata-rata skor sebesar 79,17\% (Valid). Setelah LKS direvisi berdasarkan saran dan komentar yang diperoleh dari hasil validasi pertama, maka selanjutnya akan dilakukan validasi kedua dengan memperoleh rata-rata skor sebesar 88,33\% (Valid). Selanjutnya, diperoleh rata-rata akhir uji validasi materi sebesar 83,25\% (Valid). Selanjutnya dapat dilihat pada validasi kedua, peneliti tidak melakukan validasi dengan validator 3 dikarenakan menurut beliau pada validasi pertama produk sudah dinyatakan valid. Segala saran dan komentar yang diberikan oleh validator 3 sudah diperbaiki pada validasi kedua. Hasil penghitungan validasi pertama dan kedua lembar kerja siswa (LKS) sudah sangat layak digunakan untuk pembelajaran, semua data dari hasil review, penilaian, dan diskusi dengan ahli desain dijadikan bahan pertimbangan penyempurnaan komponen lembar kerja siswa (LKS) sebelum digunakan oleh siswa. Ketiga, validasi bahasa dilakukan oleh dua orang ahli dalam menilai Pedoman Umum Ejaan Bahasa Indonesia (PUEBI). Penghitungan persentase pada validasi pertama diperoleh rata-rata skor sebesar 79,17\% (Valid). Setelah LKS direvisi berdasarkan saran dan komentar yang diperoleh dari hasil validasi pertama, maka selanjutnya akan dilakukan validasi kedua dengan memperoleh rata-rata skor sebesar 83,33\% (Valid). Selanjutnya diperoleh rata-rata akhir uji validasi materi sebesar 81,25 (Valid). Hasil penghitungan validasi pertama dan kedua lembar kerja siswa (LKS) sudah sangat layak digunakan untuk pembelajaran, semua data dari hasil review, penilaian, dan diskusi dengan ahli desain dijadikan bahan pertimbangan penyempurnaan komponen lembar kerja siswa (LKS) sebelum digunakan oleh siswa. Setelah dilakukan validasi oleh ahli desain, ahli materi, dan ahli bahasa selanjutnya dilakukan respon guru dan peserta didik yang terdiri dari dua orang guru dan enam orang peserta didik kelas IV. Adapun respon yang diberikan oleh guru dan peserta didik dapat dilihat pada tabel 2 dan 3.

Tabel 2. Respon Wali kelas IV

\begin{tabular}{|c|c|c|c|}
\hline No & Aspek Penilaian & Guru I & Guru II \\
\hline 1 & Pengorganisasian Materi & $92 \%$ & $92 \%$ \\
\hline 2 & Evaluasi dan Latihan & $96 \%$ & $92 \%$ \\
\hline 3 & Produk LKS & $100 \%$ & $91,4 \%$ \\
\hline 4 & Efek Bagi Pengguna & $86,6 \%$ & $93,3 \%$ \\
\hline \multirow{2}{*}{\multicolumn{2}{|c|}{ Rata-Rata }} & $93,65 \%$ & $92,2 \%$ \\
\hline & & \multicolumn{2}{|c|}{$92,93 \%$} \\
\hline & Kriteria & Menarik & \\
\hline
\end{tabular}

Tabel 3. Respon Peserta Didik Kelas IV

\begin{tabular}{lcclll}
\hline No & Nama & Jumlah & Skor Maksimal & Presentasi & Kriteria \\
\hline 1 & DA & 9 & 10 & $90 \%$ & Sangat Menarik \\
2 & FIR & 8 & 10 & $80 \%$ & Menarik \\
3 & AAR & 10 & 10 & $100 \%$ & Sangat Menarik \\
4 & ANR & 9 & 10 & $90 \%$ & Sangat Menarik \\
5 & RNP & 10 & 10 & $100 \%$ & Sangat Menarik \\
6 & SA & 10 & 10 & $100 \%$ & Sangat Menarik \\
\hline & Jumlah Skor & $\mathbf{5 6}$ & $\mathbf{6 0}$ & $\mathbf{9 3 , 3 3 \%}$ & Sangat Menarik
\end{tabular}

Dari tabel 2 rata-rata yang diberikan guru kelas IV sebesar 92,93\%, sehingga diperoleh kategori "Sangat Menarik". Sejalan dengan pendapat guru yang menyampaikan bahwa LKS ini menarik, perhatian peserta didik untuk belajar dan tingkat keinginan peserta didik belajar meningkat. Peneliti juga melakukan penilaian untuk mendapatkan respon peserta didik terhadap LKS ini. Tabel 3 hasil uji coba lapangan skala terbatas yang melibatkan 6 orang peserta didik menunjukkan hasil jumlah skor 56 dari skor maksimal pernyataan adalah 60. Selanjutnya diketahui bahwa tanggapan peserta didik dari uji coba skala terbatas ini diperoleh rata-rata persentase penilaian sebesar 93,33\% dengan kriteria "Sangat Menarik". Hal ini sejalan dengan pendapat peserta didik pada saat mengikuti uji coba skala kecil. Menurut mereka, LKS pada mata pelajaran Matematika dengan materi bangun datar ini menarik jika diterapkan dalam proses pembelajaran selanjutnya karena di dalamnya terdapat video serta gambar yang membuat mereka tertarik dalam pengerjaan tugas. Di samping itu, petunjuk dalam LKS ini jelas dan terarah, sehingga mereka dapat belajar dan mengerjakan tugas dengan semangat. Jadi, dapat dikatakan bahwa LKS 
yang dikembangkan valid dari aspek desain, materi, dan bahasa degan kategori yang sangat baik. Selain itu, respon guru dan siswa juga menununjukkan respon yang baik.

Hasil penelitian ini tidak terlepas dari tahap-tahap penelitian yang dilakukan. Dengan menganalisis kebutuhan, karakteritik dan kurikulum tentunya LKS yang dikembangkan, maka LKS layak digunakan. Menghasilakan media yang layak tidak terlepas dari karakter siswa yang akan menggunkan LKS tersebut. Penyusunan LKS dapat dirancang disesuaikan dengan kondisi kegiatan yang akan dilakukan dan memerhatikan perkembangan dan karakteristik peserta didik (Gitriani et al., 2018). Dengan mengetahui karakteritik siswa akan mampu mendesain LKS sesaui dengan karakteritik siswa serta penggunaan bahasa pun bisa disesauikan dengan kemampuan siswa. LKS yang sesuai dengan kempuan siswa dan didesain sesuai dengan karakteristik siswa tentunya akan membuat LKS lebih menarik. Lembar Kerja Siswa yang menarik dapat berefek terhadap proses pembelajaran. LKS merupakan salah satu alat untuk membantu dan memudahkan kegiatan pembelajaran sehingga terbentuk interaksi yang efektif antara pendidik dan peserta didik. Keberadaan LKS memberi dampak yang cukup besar dalam kegiatan pembelajaran. Lembar kerja siswa dapat menjadi panduan siswa dalam melakukan aktivitas pembelajaran (Andarika \& Widowati, 2017; Ardina \& Sa'dijah, 2016). Penggunaan LKS dalam proses pembelajaran mampu membuat siswa belajar lebih mandiri (Hamdu \& Rostiana, 2020; Pratiwi \& Yulkifli, 2019). LKS mampu mempermudah siswa mengonstruksi pengetahuan, memiliki retensi, dan meningkatkan hasil belajar siswa (Hala et al., 2016; Suryani et al., 2019). LKS yang digunakan haruslah efektif, efisien, serta mampu menjawab kebutuhan siswa dalam memahami suatu materi pembelajaran (Hasanah et al., 2019). Dengan LKS yang lebih efektif dan menarik akan melatih kemandirian siswa dalam proses pembelajaran yang mencerminkan siskap kreatif, kritis, dan lebih bertanggungjawab (Fajriyanti et al., 2018). LKS dapat meningkatkan keterampilan belajar siswa dengan pola pikir yang terbuka, kritis, dan aktif dalam proses pembelajaran (Priscylio et al., 2019). Jadi, LKS dapat meningkatkan proses pembelajaran, sehingga penyusunan LKS harus memenuhi berbagai persyaratan tertentu agar menjadi LKS yang berkualitas.

Hasil penelitian ini diperkuat oleh hasil penelitian yang sudah ada sebelumnya yang menyatakan bahwa LKPD yang didesain dan diujicobakan kepada siswa kelas VII di salah satu sekolah di Soppeng telah memenuhi kriteria valid, efektif, dan praktis (Basri et al., 2020). Penelitian yang menyatakan bahwa Lembar Kerja Siswa (LKS) pada materi Limas yang dikembangkan menggunakan pendekatan Pendidikan Matematika Realistik Indonesia (PMRI) untuk siswa kelas VIII SMP terkategori valid, praktis, dan efektif (Isnaini \& Afgani, 2017). Penelitian yang menyatakan bahwa pengembangan LKS learning cycle 7e dalam meningkatkan berpikir kritis siswa di sekolah dasar dikategorikan valid, praktis, dan efektif digunakan (Yaldi \& Sukriadi, 2019). Penelitian yang menyatakan bahwa LKS model blended learning yang berorientasi HOTS pada pokok bahasan impuls dan momentum layak untuk dipakai dalam kegiatan pembelajaran (Paradita \& Suana, 2019). Penelitian yang menyatakan bahwa LKS berbasis CTL ini dinilai baik pada semua indikator penilaian yang dilakukan oleh validator (ahli media pembelajaran, ahli materi pembelajaran, guru biologi, dan teman sejawat) serta LKS yang dikembangkan efektif digunakan untuk meningkatkan penalaran saintifik siswa(Lamapaha, 2017). Jadi, dengan mengembangkan LKS sesuai dengan karakteritik siswa, materi, dan kebutuhan akan lebih efektif digunakan.

\section{SIMPULAN}

Lembar kegiatan siswa (LKS) dengan materi bagun datar yang dikembangkan valid dari aspek desain, materi, dan bahasa dengan kategori yang sangat baik. Selain itu, respon guru dan siswa juga menununjukkan respon yang baik. Dengan adanya LKS yang lebih efektif dan sesaui dengan karakteritik siswa tentunya akan membuat pembelajaran lebih menarik. Oleh sebab itu, direkomendasikan kepada guru agar berupaya mengembangkan LKS yang sesuai dengan karakteritik siswa serta dibuat lebih menarik agar siswa lebih senang dalam proses pembelajaran.

\section{DAFTAR PUSTAKA}

Andarika, N., \& Widowati, H. (2017). Pengembangan Lembar Kegiatan Siswa (Lks) Berbasis Inkuiri Studi Kasus Pembelajaran di Kelas X Sman 6 Metro Tahun Pelajaran 2013/2014. BIOEDUKASI (Jurnal Pendidikan Biologi), 5(2), 87. https://doi.org/10.24127/bioedukasi.v5i2.787.

Ardina, F. R., \& Sa'dijah, C. (2016). Analisis Lembar Kerja Siswa dalam Meningkatkan Komunikasi Matematis Tulis Siswa. Jurnal Pendidikan: Teori, Penelitian, Dan Pengembangan, 1(2), 171-180. https://doi.org/https://doi.org/10.17977/jp.v1i2.6119.

Basri, B., Tayeb, T., Abrar, A. I. P., Nur, F., \& Angriani, A. D. (2020). Pengembangan Lembar Kerja Peserta Didik Berbasis Masalah dalam Meningkatkan Pemahaman Konsep Aljabar. Al-Khwarizmi: Jurnal 
Pendidikan Matematika Dan Ilmu Pengetahuan Alam, 8(2), 173-182. https://doi.org/10.24256/jpmipa.v8i2.1542.

Bressington, D. T., Wong, W. kit, Lam, K. K. C., \& Chien, W. T. (2018). Concept Mapping to Promote Meaningful Learning, Help Relate Theory to Practice and Improve Learning Self-Efficacy in Asian Mental Health Nursing Students: A Mixed-Methods Pilot Study. Nurse Education Today, 60(February 2017), 47-55. https://doi.org/10.1016/j.nedt.2017.09.019.

Fajriyanti, Z. D., Ernawati, T., \& Sujatmika, S. (2018). Pengembangan LKS Berbasis Project Bas ed Learning untuk Meningkatkan Keterampilan Proses Sains Siswa SMP. JIPVA (Jurnal Pendidikan IPA Veteran), 2(2), 149. https://doi.org/10.31331/jipva.v2i2.691.

Faridah, S., Mustaji, \& Tjipto, S. W. (2019). Pengaruh Contextual Teaching and Learning terhadap Aktivitas dan Hasil Belajar Siswa pada Mata Pelajaran IPS Kelas IV Sekolah Dasar. Jurnal Review Pendidikan Dasar: Jurnal Kajian Pendidikan Dan Hasil Penelitian, 5(3), 1092. https://doi.org/10.26740/jrpd.v5n3.p1092-1099.

Gitriani, R., Aisah, S., Hendriana, H., \& Herdiman, I. (2018). Pengembangan Lembar Kerja Siswa Berbasis Pendekatan Kontekstual pada Materi Lingkaran untuk Siswa SMP. Jurnal Review Pembelajaran Matematika, 3(1), 40-48. https://doi.org/10.15642/jrpm.2018.3.1.40-48.

Hala, Y., Mushawwir Taiyeb, A., Negeri, S., Biologi, J., \& Negeri Makassar, U. (2016). Pengaruh Penggunaan Lembar Kerja Peserta Didik Berbasis Pendekatan Ilmiah terhadap Aktivitas dan Hasil Belajar IPA Biologi Kelas VII Peserta Didik SMP Negeri 2 Watampone. Jurnal Sainsmat, V(1), 45.

Hamdu, G., \& Rostiana, N. I. (2020). Desain Lembar Kerja Siswa pada Pembelajaran Stem untuk Siswa Sekolah Dasar. Refleksi Edukatika: Jurnal Ilmiah Kependidikan, 11(1), 79-87. https://doi.org/10.24176/re.v11i1.4809.

Hasanah, S. I., Hafsi, A. R., \& Zayyadi, M. (2019). Pengembangan Lembar Kerja Siswa Berbasis Etnomatematika dalam Membangun Pemahaman Konsep Siswa. Jurnal Pendidikan Matematika Dan IPA, 10(2), 21. https://doi.org/10.26418/jpmipa.v10i2.29609.

Isnaini, M., \& Afgani, M. W. (2017). Pengembangan Lembar Kerja Siswa pada Materi Limas Menggunakan Pendekatan Pendidikan Matematika Realistik Indonesia (Pmri). Metodik Didaktik: Jurnal Pendidikan Ke-SD-An, 12(2). https: //doi.org/10.17509/md.v12i2.7679.

Kostiainen, E., Ukskoski, T., Ruohotie-Lyhty, M., Kauppinen, M., Kainulainen, J., \& Mäkinen, T. (2018). Meaningful Learning in Teacher Education. Teaching and Teacher Education, 71, 66-77. https://doi.org/10.1016/j.tate.2017.12.009.

Lamapaha, Y. F. (2017). Pengembangan Lembar Kerja Siswa Berbasis Kontekstual Berorientasi Penalaran Saintifik Developing of Contextual-Based Student Worksheet Oriented to Reasoning Scientific. Pendidikan Matematika Dan Sains, 5(1), 58-68.

Mustika, D. (2017). Pembelajaran Menggunakan Model Learning Cycle 5E Untuk Meningkatkan Hasil Belajar IPA Di Sekolah Dasar. Jurnal Handayani, 7(2), 1-10. https://jurnal.unimed.ac.id/2012/index.php/handayani/article/view/7230/9476.

Pane, A., \& Dasopang, M. D. (2017). Belajar dan Pembelajaran. FITRAH:Jurnal Kajian Ilmu-Ilmu Keislaman. https: //doi.org/10.24952/fitrah.v3i2.945.

Paradita, Z., \& Suana, W. (2019). Pengembangan Lembar Kerja Siswa Berorientasi Higher Order Thinking Skills pada Materi Impuls dan Momentum. Gravity: Jurnal Ilmiah Penelitian Dan Pembelajaran Fisika, 5(2). https://doi.org/10.30870/gravity.v5i2.5389.

Pratiwi, N., \& Yulkifli, Y. (2019). Peningkatan Kompetensi Keterampilan Peserta Didik Berbantuan LKPD Berbasis Model Discovery Learning pada Materi Fluida. Indonesian Journal of Science and Mathematics Education, 2(1), 130-139. https://doi.org/10.24042/ijsme.v2i1.4219.

Priscylio, G., Eriani, P., Ellizar, E., \& Andromeda, A. (2019). Pengembangan Lembar Kerja Siswa Berbasis Problem Based Learning pada Topik Ikatan Kimia. JTK (Jurnal Tadris Kimiya), 4(1), 1-10. https://doi.org/10.15575/jtk.v4i1.4085.

Septian, R., Irianto, S., \& Andriani, A. (2019). Pengembangan Lembar Kerja Peserta Didik (LKPD) Matematika Berbasis Model Realistic Mathematics Education. Jurnal Educatio FKIP UNMA, 5(1), 59-67. https://doi.org/10.31949/educatio.v5i1.56.

Septina, N., Farida, F., \& Komarudin, K. (2018). Pengembangan Lembar Kerja Siswa dengan Pendekatan Saintifik Berbasis Kemampuan Pemecahan Masalah. Jurnal Tatsqif, 16(2), 160-171. https://doi.org/10.20414/jtq.v16i2.200.

Suryani, I., Mardiati, Y., \& Herlanti, Y. (2019). Pengaruh Penggunaan Lembar Kerja Siswa (LKS) Berbasis Kontekstual terhadap Hasil Belajar Siswa pada Konsep Sistem Gerak Manusia. Edusains, 8(2), 150-156. https://doi.org/10.15408/es.v8i2.1823.

Widodo, S. (2017). Pengembangan Lembar Kegiatan Peserta Didik (LKPD) Berbasis Pendekatan Saintifik untuk Meningkatkan Keterampilan Penyelesaian Masalah Lingkungan Sekitar Peserta Didik di 
Sekolah Dasar. JPIS Jurnal Pendidikan Ilmu Sosial, 26(2), 189-204.

Widyanto, I. P. (2020). Peningkatan Mutu Pendidikan Hindu Melalui Pengelolaan Pembelajaran. Jurnal Penjaminan Mutu, 6(1), 48. https://doi.org/10.25078/jpm.v6i1.1151.

Yaldi, N., \& Sukriadi, H. (2019). Pengembangan LKS Learning Cycle 7E dalam Meningkatkan Berpikir Kritis Siswa di Sekolah Dasar. Jurnal Basicedu, 3(3), 990-993. https://jbasic.org/index.php/basicedu/article/view/223/pdf. 